In Philosophical Approaches to Proper Names, P. Stalmaszczyk and L. Fernández Moreno (eds.).Peter Lang, 2016.

\title{
Truths Containing Empty Names
}

\section{Michael McKinsey}

\section{A problem for direct reference.}

According to the thesis of Direct Reference (or the DR-thesis for short), the propositions expressed by sentences containing the proper names and indexical pronouns of natural language are a strict function of the semantic referents of the names and indexicals, as opposed to being a function of any Fregean descriptive senses or contents that the names and indexicals might be alleged to possess. ${ }^{1}$ Another way of expressing this idea is to say that the sole semantic contribution that a proper name or indexical can make to the propositions expressed by sentences containing the term is the term's semantic referent. Bertrand Russell called terms of this sort 'names in the logical sense' $(1918,201)$. I will call them 'genuine terms'. Following standard practice, I will call the propositions expressed by sentences containing genuine terms, 'singular propositions'.

Like many others, I endorse the DR-thesis. In my case, the primary reason for endorsing the thesis lies in the modal considerations first briefly introduced by John Searle (1958) and later clarified and forcefully applied by Saul Kripke (1972a), considerations which show that proper names do not have the meanings of contingent definite descriptions. David Kaplan (1989) raised related points to support the conclusion that indexical pronouns are also genuine terms.

In recent work I have argued at some length that the DR-thesis entails both that (a) a sentence containing a non-referring name or indexical can express no proposition, and hence that (b) such sentences can have no truth value, that is, can be neither true or false. (See McKinsey 2006 and (manuscript).) ${ }^{2}$ Following Braun (1993), we can call (a) the "noproposition' view. It certainly seems that the no-proposition view follows immediately from the DR-thesis. After all, if the proposition expressed by a sentence containing a genuine term is a function of the term's referent, and yet the term has no referent, then the sentence can express no proposition: a function without an argument can have no value.

\footnotetext{
${ }^{1}$ The expression 'direct reference' is due to David Kaplan (1989).

2 In past work, I simply assumed that (a) and (b) are entailed by the DR-thesis, the entailment being so immediate and obvious that it required no justification. See for instance McKinsey (1978, 180-181), (1984, 500), (1986, 170), (1994, 313), and (1999, 542-543).
} 
Nevertheless, the no-proposition view, as so far stated, is pretty obviously false. The standard counterexamples to the no-proposition view (and hence to the DR-thesis) consist of a range of fairly commonplace types of sentence that contain empty (non-referring) names, but that certainly do seem to express true or false propositions. Consider for instance:

(1) Santa Claus exists.

(2) Santa Claus does not exist.

(3) Sylvia believes that Santa Claus has a white beard.

(4) Sherlock Holmes is a fictional detective.

(5) Zeus is the most powerful of the Greek gods.

All of (1)-(5) as well as many, many other examples of a similar sort, are counterexamples to the no-proposition view and the DR-thesis, as so far stated. Positive and negative existence claims that contain empty names can express truths, as does (2), and falsehoods, as does (1). Cognitive ascriptions like (3) which contain small scope empty names can nevertheless be true (or false). Names from fiction can be used to express truths (or falsehoods) about fiction, as does (4), and names from myth can be used to express truths (or falsehoods) about myth, as does (5).

In this chapter, I will defend the view that sentences like (1)-(5) sometimes have meanings on which they semantically express true or false propositions. However, I also hold that such uses of names are relatively rare, being restricted to only a few types of contexts having forms like (1)-(5). Such uses are also (in most cases) derivative from their standard and more fundamental use as genuine terms. Thus I hold that the empty names in such sentences as (1)-(5) are not really being used as genuine terms, not really even being used as names, where again, a term is used as a genuine term or as a name, only when the term's sole propositional contribution is the term's semantic referent (if any). ${ }^{3}$

Given such examples as (1)-(5), the DR-thesis should be expressed in a slightly qualified manner:

(DR) The proper names and indexical pronouns of natural languages, in their typical and most fundamental uses, are used as genuine terms.

Similarly, we can state a counterexample-free version of the no-proposition view as follows:

(NP) Any sentence or use of a sentence that contains a non-referring name or indexical that is being used as a genuine term, fails to express a proposition.

\footnotetext{
${ }^{3}$ I provide a detailed account of what it is to use a term as a proper name in McKinsey (2010).
} 
My main goal here will be to describe and explain how certain features of natural languages in certain restricted specific circumstances give rise to idioms that allow some proper names to be used in certain forms of sentence, not as the names they are typically used as, but in such a way that the names' ordinary referents (if any) are not relevant to determining the propositions expressed by the sentences in question. My overall view will be that the idioms in question allow names to be used in contexts like (1)-(5) as short for definite descriptions. In such cases, I shall assume, the descriptions abbreviated by the names should be understood in accordance with Russell's (1905) theory of descriptions, so that failure of the descriptions to refer will not prevent sentences like (1)-(5) from expressing true or false propositions (unlike Frege's (1892) or Strawson's (1950) theories of descriptions). After I've explained and defended my overall view, I will go on to explain and argue for my view of the ways we use names from myth and fiction, and I will argue against the commonly held view that in such uses, we use these names as genuine terms to refer to abstract mythical beings and abstract fictional characters.

\section{Two ways of using names in existentials.}

When considering the semantics of positive and negative existential sentences containing names, sentences such as (1) and (2), it is important to be clear about the contrast between the meaning of such sentences when the names in them are being used as genuine terms, as names, on the one hand, and their meaning when used to state some interesting discovery, or to address the topic of some perhaps controversial debate or dispute about existence, on the other. I believe that Alvin Plantinga (1974, 137-148) was the first to clearly explain the contrast, and my discussion will in part be based on his. ${ }^{4}$

Consider the following existentials containing names:

(6) Obama exists.

(7) Obama does not exist. ${ }^{5}$

\footnotetext{
${ }^{4}$ I think it likely that Russell had a similar account in mind in his discussion of 'Romulus existed' (1918, 242-243). But Russell's discussion is very unclearly expressed.

${ }^{5}$ Here, in both (6) and (7), as well as in the discussion to follow, I am not using 'exist' in the present tense. Rather, I am using 'exist' in a tenseless sense, so that where $a$ is a singular term, ' $a$ exists' means 'For some time $t, a$ exists at $t$ '. Similarly, ' $a$ does not exist' means 'There is no time $t$ such that $a$ exists at $t$ '. I adopt this practice for two reasons. First, in serious discussions about existence, we are usually not interested merely in whether a given object exists now. For instance, in debates about whether or not God exists, we are not debating about whether God exists now, but about whether God exists at all, at any time. Second, it is only in the tenseless sense of 'exist' that a term $a$ has a referent if and only if the referent of $a$ exists, an assumption that I make throughout the chapter. Since it is obvious that we use terms to refer to things that existed in the past, the referents of such uses exist only in the tenseless sense.
} 
Suppose that I utter (6) assertively, using 'Obama' as a name, as a genuine term, to refer to the $44^{\text {th }}$ President of the United States. In doing so, I would be asserting a perfectly fine and true singular proposition about Obama to the effect that he has the property of existence. But using (6) out of the blue to assert this proposition would normally be a peculiar thing to do. For in using (6) this way, I would be presupposing its truth: in using 'Obama' as a name of Obama, I would be presupposing his existence, so that I could then go on to (redundantly) predicate existence of him. To be sure, as Plantinga points out (p. 145), there are other cases where expression of such a proposition, as opposed to its assertion, seems quite natural, as in (8) It is necessarily true that if Obama is a politician, then he exists.

But for my purposes here, the most important fact about sentences of the form ' $a$ exists', where $a$ is used as a name, is that unless they are true, such sentences can be used to say nothing at all, and would thus have no truth value. For if ' $a$ exists' is not true, $a$ has no referent, and then ' $a$ exists' would express no proposition. ${ }^{6}$ Thus such sentences cannot be false, when used assertively by a speaker in the actual world. ${ }^{7}$ That is why it is pointless to use such sentences assertively.

Assertive uses of negative existentials like (7) are even more peculiar, given that the names they contain are being used as genuine terms. It would of course be absurd to refer to Obama with his name, only to go on to falsely claim that he does not exist. So such sentences cannot be true when used by a speaker in the actual world. (If 'Obama' refers, the sentence is false; if 'Obama' does not refer, then the sentence has no truth value.) In this case, it is not just pointless, but it is pragmatically inconsistent to use such sentences assertively. ${ }^{8}$ Once again, however, (7) like (6) expresses a perfectly good (though false) proposition, and also like (6) there are contexts in which use of (7) to express this proposition is perfectly natural, as in

(9) Though Obama exists, it's possible that he does not exist. ${ }^{9}$

I will say that existentials like (6) and (7), when the contained name is used as a genuine term, are assertively pointless, in the sense that they either cannot be used to assert anything true (as in (7)) or they cannot be used to assert anything false (as in (6)).

\footnotetext{
${ }^{6}$ Note again that here, ' $a$ exists' is tenseless.

${ }^{7}$ Though sentences like (6) can be false on modal interpretations, since they will be false at worlds in which the actual referent of the relevant name (in this case Obama) fails to exist.

${ }^{8}$ Though again, on modal interpretations such sentences can be true at worlds in which the actual referent of the relevant name (in this case, Obama) fails to exist.

${ }^{9}$ This is similar to the valuable point first made by G.E. Moore regarding the significance of 'This does not exist'. See Moore $(1936,123)$.
} 
As Plantinga points out, there is an enormous contrast between (a) the meaning of existentials like (6) and (7) in which the names are used as genuine terms, so that the existentials are assertively pointless, and (b) the meaning of existentials of the same grammatical forms when they are used to express genuine discovery or disagreement regarding existence. Plantinga says the following about a case of the latter type $(1974,141)$ :

\begin{abstract}
Suppose a pair of classicists have a dispute as to whether or not Homer existed; it would be incorrect, I think, to represent them as referring to the same person - namely, Homer - and disagreeing as to whether that person had the property of existing. The one who takes the affirmative, I think, is not singling out or specifying a person by use of the name 'Homer' and then predicating existence of him; his opponent is not using that name to specify a person of whom he then goes on to predicate nonexistence.
\end{abstract}

I think that Plantinga is clearly right about this. It is especially obvious that no supporter of a negative existential of the form ' $a$ does not exist', where $a$ is a name, would be absurdly attempting to assert nonexistence of $a$ 's referent. But then the supporter of ' $a$ exists' would also not be trying to (pointlessly) predicate existence of the referent of $a$, since in doing so, the supporter would not be asserting what her opponent is denying.

In short, in serious discussions or disputes about existence, where the discussion or dispute is expressed by use of a proper name, the name is not being used as a name, as a genuine term. How then is the name being used? Plantinga describes three different views, those of Russell, Searle, and Donnellan, according to which the names in such contexts are in effect being used as short for various sorts of definite description. Plantinga endorses none of these views, but he does suggest that some such view must be correct (p. 146). I think that Plantinga is right about this, since, as I shall argue in sections 5 and 6 below, there in fact seems to be no reasonable alternative. It is clear that when a given name $a$ is being used in a serious discussion or dispute about existence, the speakers are not presupposing the existence of the name's referent, as they would be if the name were being used as a genuine term. On my view, the best hypothesis is that the name $a$ is being used as short for a description understood according to Russell's theory of descriptions. Understood this way, positive and negative existentials such as 'Homer existed' and 'Homer did not exist' express propositions that are either true or false, whether or not the name 'Homer' refers.

\title{
3. Descriptive names.
}

Of course, if Plantinga is right, as I think he is, then the very difficult question arises as to how directly referring names like 'Homer' should come to be meaningfully used as short for specific descriptions. What features of natural language could possibly account for its 
happening that a given proper name of a sort that is typically used as a genuine term that has no descriptive content, should nevertheless come to be useable in certain contexts (such as positive or negative existentials) as synonymous with some specific definite description?

The difficulty of this question is considerably ameliorated if we note at the outset that the vast majority of proper names that speakers commonly use as names simply cannot be reasonable candidates for acquiring the additional meaning of a specific definite description.

If a single description commonly associated with a name by speakers of a given language did in fact determine or fix the semantic reference of that name, then of course that description would be a semantically salient feature of the name. But Kripke (1972a) provided strong evidence that the reference of most names is not determined or fixed by any commonly associated descriptions. He did this with his famous Gödel-Schmidt case, and other cases like it. Practically the only thing that most speakers know about Gödel is that he discovered the incompleteness of arithmetic. But as Kripke points out, speakers' uses of 'Gödel' would still refer to Gödel even if not Gödel but an unknown high school teacher named 'Schmidt' had discovered that arithmetic is incomplete. Since the same point can be made regarding all the accomplishments for which Gödel is famous, it is clear that the semantic referent of 'Gödel' is not determined by any description like 'the discoverer of incompleteness' that might be commonly associated with the name. So it surely seems that the referents of most proper names are not determined by any commonly associated descriptions. Thus, in the case of most names, there will simply be no semantically salient description that would allow us to interpret positive or negative existentials containing the name as expressing anything other than an assertively pointless proposition.

Nevertheless, as I have argued elsewhere (McKinsey 1999), there do exist names of natural language which are both used as genuine terms and whose referents are determined or fixed by commonly associated definite descriptions. I call such names 'descriptive names'. Names like this are in fact exceedingly rare, though in the examples of philosophers, they are not rare but frequent. For as we shall see, it is precisely the members of this relatively small class of names which provide most of the examples of names like 'Homer' that can be used in positive and negative existentials that are substantive rather than pointless, and which, when they lack referents, can provide examples of truths and falsehoods that contain empty names, such as (1), (2), (3), and (5) above.

The crucial common feature of descriptive names is that their referents (if any) are epistemically remote from all speakers in the same way, so that the users of such a name have to base their referring use of the name on the same small set of properties or descriptions. A 
good example of this, suggested by Kripke $(1972,291)$ is the name 'Jack the Ripper', used to refer to whoever committed the grisly murders of a specific group of prostitutes in Victorian era London, but about whom nothing else is known. The two names of the planet Venus, 'Hesperus' and 'Phosphorus', are also good examples, especially as they were used by the ancient Greeks, since cognitive access to Venus was then based solely on sightings of the planet in different locations of the sky and at different times of day. Other good candidates for being descriptive names would include: 'Vulcan' (used as the name of an alleged planet between Mercury and the Sun); names of deities, such as 'Zeus' and 'God'; names of mythical persons and creatures, such as 'Faffner' and 'Pegasus'; names of historically remote figures about whom little is known, like 'Homer', 'King Arthur', and 'Robin Hood'; and pen names such as 'Mark Twain' and 'George Sand', at least before their referents' identities become publically known.

Note that my examples of descriptive names do not include any names from fiction, such as 'Sherlock Holmes'. Our use of such names to talk about fiction, as we shall see in section 8 , is not at all based on any actual speakers' referential uses of the names as names that happen to be descriptive in the sense I just explained.

Whether or not a name is descriptive is of course always an empirical question. But we can sometimes provide good evidence to settle the question by using a strategy derived from Kripke's Gödel-Schmidt case. (Again, see McKinsey1999, 536-538.) In that case, we ask whether or not it is consistent with the way we actually use the name 'Gödel' to suppose that it is not Gödel who uniquely satisfies a given description 'The F', but rather it is someone else, Schmidt say, who uniquely satisfies 'The F'. If the answer is 'Yes', then the description 'The F' is irrelevant to determining the reference of 'Gödel'. But if the correct answer is 'No', then the name is descriptive.

Consider, for instance whether the following expresses a live semantic possibility:

(10) It wasn't Jack the Ripper who murdered all those prostitutes in Victorian era London; rather, those murders were all committed by some other man named 'Schmidt'.

Such a pronouncement strikes me as absurdly false, but not because it expresses an impossible proposition. It is absurd simply because if Schmidt had committed the relevant murders, then he would just be Jack the Ripper, the very one to whom we had been referring all along with that name. Thus even though there are possible worlds in which Jack did not do the heinous deeds, the actual semantics of the name 'Jack the Ripper' guarantees that (10) is false. Thus, 'Jack the Ripper' is a descriptive name. 
It is worth noting that descriptive names can either refer or fail to refer, depending on whether the description that determines or fixes the referent of the name is or is not uniquely satisfied. In either case, if the name is descriptive it will pass the Gödel-Schmidt test. For example, it surely seems that the name 'God' passes the test, since it would I think be absurd to say:

(11) It isn't God who is the purely spiritual, omniscient, omnipotent, maximally benevolent creator of the universe by intelligent design; rather, it is some other being (named 'Schmidt'?) who has these characteristics.

Whether or not one believes that God exists, one can see the semantic absurdity of (11) and hence can see that the name 'God' is descriptive, whether it refers or not.

\section{The idiomatic use of descriptive names.}

I should emphasize that on the view I have been outlining and motivating, descriptive names like 'Homer' and 'Jack the Ripper' are in the first place used as genuine terms, and as such function only to introduce referents into the propositions expressed by sentences containing the descriptive names. The descriptions that are commonly associated with descriptive names serve only to fix the reference of the relevant names, for each individual user of the name. There is no sense in which the description that fixes the reference of a given descriptive name provides the meaning of that name, as it is used as a genuine term. That a given name is descriptive is thus, I take it, solely a matter of fact, and not a matter of meaning. The fact that matters, as I mentioned earlier, is the epistemic remoteness of the name's putative referent. It may be that there is little or even no good evidence for the putative referent's existence, as in the case of names of historically remote persons and the beings of religion and myth. Here, names' referents (if any) must be fixed either by the scant historical evidence, or by the narrow confines of myth or religious doctrine. On the other hand, there may be very good, even conclusive, evidence for the referent's existence, as in cases like 'Jack the Ripper' and 'Hesperus'; but here, the body of good evidence is itself very small, so that all users of the name must base their reference with the name on a narrow class of descriptions or properties.

Given the existence of a class of descriptive names, each of which has its semantic referent determined by a commonly associated description, each such description will become a semantically salient feature of the relevant name, for the speakers of a given language. My hypothesis is that in such conditions it is natural for a general idiomatic 
convention to arise on which each descriptive name is allowed, in certain types of sentential contexts, to be used as short for the description that normally fixes the name's reference. I will call this 'the idiom hypothesis'. As far as I can tell, there are just three types of context in which a descriptive name is allowed to be used as short for the relevant description: (i) existential contexts, where as we've seen, use of a descriptive name as short for the relevant description allows speakers to use a positive or negative existential containing the name to express or assert interesting discoveries or subjects of significant debate regarding existence, as opposed to expressing assertively pointless propositions; (ii) cognitive contexts, such as sentence (3) above, in which a small scope descriptive name's use as short for a description can be used to express an agent's way of thinking about a (putative) object without committing the speaker to such an object's existence; and (iii) contexts involving the use of names from myth to talk about what is true (or false) in a given myth. (Note again that the idiom just described does not apply to uses of names from fiction.)

One of the most important consequences of my idiom hypothesis is that when we ask, say, whether Homer existed or not, we are in effect also asking whether the reference condition for the descriptive genuine term 'Homer' is uniquely satisfied or not. Suppose the reference condition for this type of use of 'Homer' is that 'Homer' is to refer to a given object $x$ iff $x=$ the poet of ancient Greece named 'Homer' who composed the Iliad and the Odyssey. Abbreviate this description as 'the F'. Then we have the consequence that 'Homer' refers iff the F exists. In everyday parlance, this equivalence would be expressed as: 'Homer' refers iff Homer exists. It is commonly assumed that in such locutions, the name referred to is semantically the same as the name that is used in the relevant existential. This is a serious error. For in these locutions, the name 'Homer' referred to is a directly referring genuine term, while the 'name' used in the relevant existential is not used as a name at all, since it abbreviates 'the F'.

\section{An alternative pragmatic explanation.}

A few defenders of the DR-thesis have suggested that, while some sentences containing empty names may appear to be true (or false), such sentences never literally express true or false propositions. Fred Adams and Robert Stecker (1994) suggest that a sentence like

(12) Vulcan does not exist,

may appear to express a true proposition, but this is only because use of the sentence will "pragmatically impart" such information as that there is no planet between Mercury and the 
sun (p. 313). They allege that this sort of pragmatic fact explains why people (like me) have the mistaken intuition that (12) is true (p. 394).

Of course on my view, Adams and Stecker are wrong. 'Vulcan' is a descriptive name in its use derived from the astronomer Le Verrier, since on this use, the semantic reference of 'Vulcan' is fixed for most speakers by the description 'the planet whose orbit between Mercury and the sun explains discrepancies in the orbit of Mercury'. Given the idiom hypothesis, 'Vulcan' is used as short for this description in (12), so that on one of its meanings, this sentence in fact expresses the true proposition that

(13) The planet whose orbit between Mercury and the sun explains discrepancies in the orbit of Mercury does not exist.

But why prefer my idiom hypothesis to a view like that of Adams and Stecker? I think the main reason is that, as Adams and Stecker agree, it is extremely counterintuitive to claim that no negative existential that like (12) contains an empty name is ever true. (See also Adams and Dietrich 2004, 126.) Attempts to explain away the intuition that many negative existentials such as (12) are true are in my opinion unpersuasive, given the robustness, persistence, and pervasiveness of this sort of intuition. My view has the distinct advantage of explaining how such intuitions can be correct, while requiring only minimal revision of the DR-thesis. (See principles (DR) and (NP) above.)

Adams and Stecker seem to be worried that if they accepted the idea that a negative existential like (12) expressed a descriptive proposition like (13), then they would be committed to a short for descriptions theory of names, which (like me) they correctly think is false $(1994,394)$. But this worry is misplaced. Again my view is that names are typically and fundamentally used as genuine terms, and in such uses they are of course never short for descriptions. But this allows for a statistically rare class of exceptions, where in a few types of context (existentials, cognitive ascriptions, and talk about myth), a small class of descriptive names are idiomatically allowed by the conventions of natural language to be used as short for descriptions.

A second reason why I prefer the idiom hypothesis is that I have yet to see a plausible pragmatic explanation of why we persistently have the firm intuition that sentences like (12) are true. Adams et al. merely rely on the fact that various descriptions are often associated with empty names. But as Mitchell Green (2007, 432-433) has pointed out, it is difficult to see how mere association of 'Vulcan' with a given description could cause one to think that 'Vulcan does not exist' is true, given that one did not think this in the first place. Adams and 
Dietrich (2004, 145, note 7) suggest that their associated-descriptions explanation is somehow Gricean in nature, but in fact Adams et al. never explicitly make any use of Grice's ideas.

Still, it is useful to consider how the intuition that 'Vulcan does not exist' is true might be given a Gricean explanation. If, like Adams and Stecker, we assume that the only literal meaning that a negative existential like (12) could have is a meaning on which the relevant name is being used as a genuine term, then when we hear someone assertively utter (12), we will take the speaker to be absurdly attempting to predicate non-existence of the referent of 'Vulcan'. Since such a sentence is at best false (when 'Vulcan' has a referent) and at worst without truth value (if 'Vulcan' is empty), the speaker is violating Grice's maxim of Quality ("speak truly"), and thus the speaker seems to be conversationally uncooperative in Grice's sense. But if the speaker otherwise seems to be cooperating, the hearer will infer that the speaker is trying to communicate something other than what (12) literally expresses. (See Grice 1989, 26-27.) Since the referent of 'Vulcan' is fixed by the description in (13), the hearer will naturally infer that by uttering (12), the speaker means the true proposition expressed by (13).

This is the best Gricean explanation of the intuition that (12) is true that I can think of. Yet the explanation is seriously defective. It assumes that one who hears a speaker assertively utter (12) will only hear the utterance either as an absurd attempt to assert a blatantly false singular proposition or as being neither true nor false. But on the contrary, I seriously doubt that anyone would ever (even tacitly) hear an assertive utterance of (12) this way. Thus my Gricean explanation simply cannot get off the ground. The speaker will not be heard as literally saying something that must be false or truth-valueless, and so will not seem to be uncooperative. So the hearer will not be driven to figure out what else the speaker might mean. On my view, an assertive utterance of (12) - where 'Vulcan' is understood as in its

uses derived from Le Verrier - is always heard in just one of its two literal meanings, namely, the descriptive meaning on which (12) means (13). The other literal meaning of (12) will simply not be heard, since being assertively pointless, it is just not ever salient.

\section{6. 'Gappy’ propositions.}

David Braun (1993) has suggested that sentences containing empty names express 'unfilled' or 'gappy' propositions that are always either true or false. The 'gap' occurs at the position in the propositional structure contributed by a sentence containing an empty name, a position that would normally be occupied by the name's referent. Braun claims that all 
atomic gappy propositions are false. If we treat 'exists' as a one-place predicate, then a sentence like 'Vulcan exists' will thus be false, and its negation (12) ('Vulcan does not exist') will thus be true. The great virtue of this view is that it allows such existential sentences that contain empty names to be true or false, as they certainly seem to be.

But despite having this virtue, Braun's view faces some serious difficulties. First, and perhaps most significant, is the fact that, given what propositions are supposed to be, there can be no propositions that are 'gappy'. For a proposition is a way that the world can be said to be. But when we use a sentence that contains an empty name that is used as a name, there is no way that the world is said to be by our use of that sentence. And so there is nothing about the way the world is that could make our sentence either true or false.

Even if we suppose that a sentence containing an empty name has some sort of semantic content, there is no reason to think that this content would be something that is true or false. I would agree with Adams and Stecker $(1994,390)$ that the semantic content of an atomic sentence containing an empty name such as 'Vulcan is a planet' is precisely the content of the corresponding open sentence ' $x$ is a planet'. Since an empty name contributes no semantic value whatever to the content of the sentence containing it, the content of 'Vulcan is a planet' would seem to just be the content of the expression that results from removing the name 'Vulcan' from the sentence. Frege famously suggested that if we remove the name from such a sentence, the result is an 'unsaturated' predicate that 'contains an empty place', which in this case could be written '( ) is a planet'. (See Frege 1891, 31.) We could instead write this as an open sentence ' $(x)$ is a planet', with the free variable ' $x$ ' marking the relevant gap. As is commonly held, I would say that such an open sentence has no truth value (except relative to an assignment of objects to the free variables).

A second difficulty with Braun's view is that he provides no good reason for his claim that gappy atomic propositions are false. Braun $(1993,463-464)$ proposes a truth condition for one-place atomic propositions from which it follows that

(14) If $\mathrm{P}$ is a one-place atomic proposition whose subject position is unfilled, then $\mathrm{P}$ is not true. $^{10}$

Braun goes on to suggest that such a gappy proposition would be false since not true. But in making the latter suggestion, Braun is choosing to ignore a falsity condition for atomic

\footnotetext{
${ }^{10}$ The full statement of truth conditions that Braun provides is:

If $\mathrm{P}$ is a proposition having a single subject position and a one-place property position, then $\mathrm{P}$ is true iff the subject position is filled by one, and only one, object and it exemplifies the property filling the property position. If $\mathrm{P}$ is not true, then $\mathrm{P}$ is false. $(1993,463$.)
} 
propositions that is exactly as plausible as (14). (14) is properly motivated, since if we assert an unfilled one-place atomic proposition, then we fail to say anything that is true of any object. But by the same token, we also say nothing that is false of any object by asserting such a proposition. Thus the same reasoning behind Braun's (14) also justifies:

(15) If $\mathrm{P}$ is a one-place atomic proposition whose subject position is unfilled, then $\mathrm{P}$ is not false. $^{11}$

Of course, putting (14) and (15) together implies that no one-place atomic proposition ever has an unfilled subject position, since if it did, that proposition would be neither true nor false and hence would not be a proposition. By merely assuming without argument that unfilled atomic propositions are false since not true, Braun has ignored one of the basic intuitions behind the no-proposition view, which I endorse. This is the intuition that an atomic sentence containing an empty name (used as a name) cannot be used to say anything false about anything, and so is not false. By ignoring this intuition, Braun has left his view without any plausible motivation. ${ }^{12}$

Finally, it should be emphasized that Braun's view cannot account for the fact, pointed out by Plantinga, that names can be used in positive and negative existentials to express substantive debates, disputes, discussions, and discoveries about existence. This is a problem facing any view (including that of Adams and Stecker) on which names can never be used as anything other than directly referring genuine terms. Braun's view would explain how sentences containing empty names can be true or false. But his view does not solve Plantinga's problem.

Consider again the two classicists who disagree about Homer's existence. Classicist A asserts that Homer existed, classicist B asserts that Homer did not exist. Given that 'Homer' refers, then on Braun's view, A can only be pointlessly asserting a singular proposition that cannot be false (in the actual world), while B can only be absurdly asserting the denial of that singular proposition, a denial that cannot be true (in the actual world). Thus Braun's view, like that of Adams and Stecker, has the false consequence that the use of referring names in positive and negative existentials is inevitably assertively pointless.

What happens when we assume that 'Homer' is empty? Then on Braun's view, A is asserting a necessarily false gappy proposition, while $\mathrm{B}$ is asserting the necessarily true

\footnotetext{
${ }^{11}$ Here is the full falsity condition:

If $\mathrm{P}$ is a one-place atomic proposition, then $\mathrm{P}$ is false iff the subject position in $\mathrm{P}$ is filled by just one object, and that object does not exemplify the property filling the property position.

${ }^{12}$ Adams and Stecker $(1994,397)$ also point out that this aspect of Braun's view is "undermotivated".
} 
denial of that gappy proposition. (See Braun 1993, 468, note 26.) Of course, neither A nor B has the slightest idea that they are respectively asserting and denying a gappy proposition that is necessarily false. So in this case, on Braun's view, A and B really have no idea whatever as to what their dispute is about, given that 'Homer' has no referent.

A similarly counterintuitive consequence also follows on the more standard view of Adams and Stecker. On that view, when 'Homer' fails to refer, neither A nor B is literally asserting any proposition at all by their uses of 'Homer exists' and 'Homer did not exist'. So there is simply nothing that their disagreement is about in this case, a consequence that is surely false.

We have just found a second problem with the idea that the names used in substantive disputes about existence are being used as genuine terms. The first problem we saw is that when the names refer, the disputes turn out to be assertively pointless (as Plantinga pointed out). The new problem is that when the names fail to refer, the participants either have no idea what their dispute is about (on Braun's view) or their dispute is in fact about nothing (on Adams and Stecker's view). In short, the problem is that if the names in the existence disputes are being used as genuine terms, then what such a dispute is literally about will depend on whether the relevant name refers or not. But whether the name refers or not is in effect precisely what the dispute is really designed to settle! (Though the dispute is certainly not metalinguistic; rather, the dispute is about whether or not the property expressed by the relevant reference-fixing description is uniquely satisfied.) My idiom hypothesis provides a salutary solution to this problem. For if the name $a$ is being used as short for a description, then the proposition expressed by ' $a$ exists' can remain the stable subject of dispute, whether or not the name $a$ refers.

\section{Names from mythology.}

Our uses of names from mythology and fiction are derived from uses of the same expressions in mythology and fiction. As we shall see, these two origins of our uses of such names are significantly different from each other, and moreover, our ways of using these two classes of names both differ significantly from our use of other empty descriptive names.

Originally, names from myth were used to express stories that were told as fact and widely believed to be fact. The names used to express such stories, and parts of such stories, were thus originally used as names, as genuine terms. These names, in my view, were all what I call descriptive names, whose referents were fixed by descriptions gleaned from the myths. Thus the names from Greek mythology could well have been used by the ancient 
Greeks to express substantive disputes as to whether, say, Zeus existed or did not exist. If so, the ancient Greek language would have contained an idiomatic convention of the kind that, on my view, exists in contemporary natural languages like English, a convention that allows descriptive names to be used in certain types of context as short for the descriptions that fix their reference.

As I suggested earlier, empty names from myth can be used by contemporary speakers in three different ways. First, there are 'metamythic' uses in which the names are used to make true (or false) statements about what is true in a given myth, ${ }^{13}$ such as

(16) In Greek mythology, Zeus is both immortal and extremely powerful.

Second, empty names from myth can be used in cognitive contexts to make true (or false) statements such as

(17) The ancient Greeks believed that Zeus is both immortal and extremely powerful.

And finally, empty names from myth can be used to make (false) positive existential statements and (true) negative existential statements, such as 'Zeus existed' and 'Zeus did not exist'.

My view is of course that in all of these three types of use, the relevant name is being used not as a name, but as short for a description. But it is a far from trivial matter to determine which description a contemporary use of a name from myth would be short for. For instance, ancient Greek users of a name like 'Zeus' would no doubt have had a far more detailed and extensive conception of the putative referent of this name than do modern users. So it seems unlikely that we use the name as short for the same, perhaps complex, description that commonly fixed the reference of the ancients' uses of 'Zeus'. Contemporary uses of such names from Greek mythology are probably based upon whatever cursory knowledge that modern speakers might have of the most important and distinctive characteristics that were alleged in the myths to be possessed by the various gods. For instance, in the myths, Zeus was considered the most powerful of the gods, a 'sky god' who controlled the occurrence of rain, thunder, and lightning. ${ }^{14}$ So one good candidate for the description that our uses of 'Zeus' might be short for would be 'the most powerful of the gods, who is named "Zeus"'. The chief criterion that any such candidate description must satisfy, is that it yield truths upon substitution for 'Zeus' in true statements about the relevant myth and about the myth's

${ }^{13}$ My coinage of 'metamythic' is derived from Currie's (1990) useful term 'metafictive' to describe statements about what is true in a given fiction. In general, metamythic and metafictive contexts are always either prefixed by explicit myth or fiction operators such as 'in myth $M$ ' or 'in fiction F', or such an operator is implicit.

${ }^{14}$ See Hamilton $(1953,27)$. 
believers' cognitive states. Substitution of the description 'the most powerful of the gods, who is named "Zeus" for 'Zeus' in (16) and (17) results in true (if somewhat redundant) statements.

Earlier, in sections 2, 5, and 6, I provided strong evidence that when descriptive names occur in substantive existentials, they are being used as short for descriptions. Once this is accepted, we then have additional evidence that empty mythical names are also used as short for descriptions in metamythic and cognitive contexts like (16) and (17). Consider sentences involving pronominal anaphora such as:

(18) Zeus does not exist, but in Greek mythology, he is both immortal and extremely powerful.

(19) Zeus does not exist, but the ancient Greeks believed that he is both immortal and extremely powerful.

Since the anaphoric pronoun 'he' has the name 'Zeus' as antecedent in both (18) and (19), it surely seems that these occurrences would just be going proxy for 'Zeus' as it is meant in the left conjuncts of (18) and (19). Thus in both cases, 'he' would be short for the same description as 'Zeus' is short for. But then, the right hand conjuncts of (18) and (19) as so understood would express the same truths as (16) and (17). So in both metamythic and cognitive contexts, names from myth are used as short for descriptions.

Kripke (2013) has persuasively argued for the view that contemporary users of names from both myth and fiction often use such names as genuine terms that refer directly to abstract mythical or fictional beings or objects. I will discuss Kripke's contention further below in section 9. But it is already apparent that in both metamythic and cognitive contexts, names from myth are not used as names of abstract objects. For instance, (16), which I take to be true, would be false if the occurrence of 'Zeus' in (16) referred to an abstract mythical being. For it is clearly not true in Greek mythology that any abstract mythical being is both immortal and extremely powerful. Nor is it true that the ancient Greeks (absurdly) believed of some abstract mythical being that it is both immortal and extremely powerful. Thus (17) would also be false, if in (17) 'Zeus' referred to an abstract mythical being. I take it that these arguments can be generalized in an obvious way to show that in no metamythic or cognitive contexts containing names from myth are the names used to refer to abstract objects. It remains to be seen whether there are any other types of contexts in which names from myth are used as names of abstract entities. Kripke clearly thinks that there are such contexts, but I disagree. I will discuss this issue at length in section 9. 


\section{Names from fiction.}

The origin of our uses of names from fiction is quite different from the origins of our uses of descriptive names, including names from myth, as short for descriptions in special contexts. These latter uses derive from real uses of the descriptive names as names, as genuine terms. But as many authors have pointed out, fictional names are never actually used as names in fiction. ${ }^{15}$ Rather, in fiction it is merely pretended that given expressions are used as names of various characters in the fictions. But since these are only pretend uses, they are not actual uses, and so they have no actual semantic properties: such uses have no referents, and sentences in fiction containing them express no propositions. ${ }^{16}$

Thus my idiom hypothesis cannot be applied to explain how we use 'names' from fiction, since these fictional names are not really used as names at all, let alone as descriptive names. The idiom that provides meanings for our uses of (syntactic) names to make true or false statements about fiction must be an idiom that is specific to talk about fiction. My hypothesis will again be that the relevant terms that we borrow from fiction to talk about fiction are used as short for descriptions. We can again justify this hypothesis for what Currie $(1990,158)$ calls 'metafictive' uses of names by using constructions involving anaphoric back-reference to negative existentials, such as

(20) Sherlock Holmes does not exist, but in the Holmes-stories, he is a brilliant detective.

Again, assuming that in the left conjunct of (20) 'Sherlock Holmes' is used as short for a definite description, then the anaphoric pronoun 'he' in the right conjunct must be short for the same description. But this right conjunct would clearly have the same meaning as

(21) In the Holmes-stories, Sherlock Holmes is a brilliant detective.

Thus, as in the metamythic cases, the 'names' used in metafictive contexts are used as short for definite descriptions.

And again, as in the metamythic cases, we can show that no 'name' used in a metafictive context is ever used as a genuine term that refers to an abstract fictional character. ${ }^{17}$ Consider, for instance

\footnotetext{
${ }^{15}$ See for instance Plantinga $(1974,159)$, Kripke $(2013,81)$, van Inwagen $(1977,301)$, and Currie (1990, 146-155).

${ }^{16}$ Here I am ignoring the names that are used in fiction as names of actual objects, such as 'Napoleon' and 'London'. These names are of course names used in fiction, but they are not fictional names.

${ }^{17}$ Contrary to the views of Salmon (1998, 302-303) and Zalta (2000, 128-129).
} 
(22) Holmes is an abstract fictional character, and in the Holmes-stories, Watson believes that Holmes plays the violin.

On the assumption that in (22) 'Holmes' is used as the name of an abstract entity, it would follow from (22) by existential generalization that

(23) $\exists x(x$ is an abstract fictional character and in the Holmes-stories, Watson believes that $x$ plays the violin).

But surely, contrary to (23), it is simply not true in the Holmes-stories that Watson has a (wildly false) belief about an abstract entity to the effect that it plays the violin.

My view of how names work in metafictive contexts is largely derived from Gregory Currie's thorough, clear, and persuasively argued theory of fiction in his book The Nature of Fiction (1990). Currie also endorses the view that in metafictive contexts, where we use 'names' derived from a given fiction to make claims about what is true in that fiction, the names are being used as short for a certain sort of definite description. As we shall see, my view of what these descriptions are differs significantly from Currie's view. But even so, my view is inspired by Currie's compelling theory of truth in fiction. I will write this theory as follows:

(TF) In fiction $\mathrm{S}$ it is true that $\mathrm{p}$ iff it is reasonable (to degree $\mathrm{r}$ ) for the informed reader of $\mathrm{S}$ to infer that the fictional author of S believes that $p$. (Currie 1990, 92.)

Currie's concept here of the fictional author of a fiction is especially important for my purposes. Currie points out that when we read a given story, we make believe that we are being told the story by a reliable teller who has complete and knowledgeable access to all the facts of the story being told. As Currie puts it:

The fictional author (as I shall call him) is that fictional character constructed within our make-believe whom we take to be telling us the story as known fact. Our reading is thus an explanation of the fictional author's belief structure. (Currie 1990, 76.)

Since the actual author of a story will not in fact believe most of the propositions that make up the story, the actual author should not be confused with the fictional author. Moreover, while some fictions have characters who narrate the fiction, as Watson narrates the Holmesstories, Currie argues that we also should not confuse the fictional author with the fictional narrator (if any): he points out ( $\mathrm{p}$ 124) that fictional narrators like Watson often have beliefs that are simply not true in the fiction. 
Currie (1990, 149-150) proposes that the total content of a given fiction is the Ramsey sentence obtained by replacing each name $t_{i}$ in the fiction $F\left(t_{1} \ldots . t_{n}\right)$ by a distinct variable and then writing the existential closure of the result, as follows: ${ }^{18}$

$$
\exists x_{1} \ldots \exists x_{\mathrm{n}}\left[\mathrm{F}\left(x_{1} \ldots x_{\mathrm{n}}\right)\right]
$$

Then (certain niceties aside), Currie uses a procedure invented by Davis Lewis (1970) to form the definite descriptions for which each metafictive use of a name from fiction is an abbreviation. Supposing for instance that ' $x_{1}$ ' is the variable that replaces 'Holmes' in the original regimentation of the fiction $\mathrm{F}\left(\mathrm{t}_{1} \ldots \mathrm{t}_{\mathrm{n}}\right)$, we can then define the name 'Holmes' thus:

$$
\text { Holmes }=_{\mathrm{df}} \quad 1 x_{1} \exists x_{2} \ldots \exists x_{\mathrm{n}}\left[\mathrm{F}\left(x_{1} \ldots x_{\mathrm{n}}\right)\right] .^{19}
$$

On this idea, every fictional name in a metafictive statement about a fiction $\mathrm{S}$ is short for a definite description that expresses the entire content of S. This has the implausible consequence that even the best informed reader would have at best only a partial and schematic grasp of the hugely complex propositions expressed by use of even quite simple metafictive sentences such as

(26) In the fiction $\mathrm{H}$, Holmes is a pipe smoker,

(where ' $\mathrm{H}$ ' refers to the fiction composed of all the Holmes-stories). But surely, a correct semantic account of the use of names in talk about fiction should not imply that, in the case of fairly long fictions, no speaker of the relevant language could possibly understand, let alone know the truth of, even the simplest metafictive sentences such as (26).

My alternative suggestion is that when a fictional name $\mathrm{N}$ from a given fiction $\mathrm{S}$ is used in a given metafictive sentence about $\mathrm{S}, \mathrm{N}$ is short for a metalinguistic description of the form 'the person [or object] to whom [or which] the fictional author of S refers with N'. I will abbreviate this form as 'the referent $\mathrm{FAS}_{\mathrm{S}}$ of $\mathrm{N}$ '. So for instance (26) would then mean

(26a) In the fiction $\mathrm{H}$, the referent $\mathrm{FAH}_{\mathrm{FH}}$ of 'Holmes' is a pipe smoker.

Similarly, the negative existential 'Holmes does not exist' would mean

\footnotetext{
${ }^{18}$ As Currie notes (p. 146), this idea was first suggested by Plantinga (1974, 159-163.)

${ }^{19}$ See Currie's definition (8) (Currie 1990, 160). The operator ' $1 x_{1}$ ' is an instance of the term forming, variable binding operator that Russell introduced in Principia Mathematica to form definite descriptions in his notation. (See Whitehead and Russell 1910, 67-84.) In general, where $v$ is any variable and $\varphi(v)$ is any formula containing $v$, ' $v$ ' can be translated as 'the object $v$ such that' and ' $v \varphi(v)$ ' as 'the object $v$ such that $\varphi(v)$ '.
} 
(27) The referent ${ }_{\mathrm{FAH}}$ of 'Holmes' does not exist.

(27) is true on my proposal, simply because the fictional author of $\mathrm{H}$, being fictional, does not exist. Hence the person to whom the fictional author of $\mathrm{H}$ refers with 'Holmes' also does not exist. Note that it turns out on my proposal not only that 'Holmes does not exist' is true, but also that it is necessarily true. Since at no possible world will there exist a fictional author of anything, the description "the person to whom the fictional author of $\mathrm{H}$ refers with "Holmes"" will fail to refer at every possible world. Thus my proposal is both consistent with and explains Kripke's important insight that not only does Sherlock Holmes not exist, but it is not even possible that he exists. (See Kripke 1972b, 764 and 2013, 40-42.)

One minor problem for my proposal is raised by the fact that there can be fictions in which two or more persons have the same name. Thus in The Adventure of the Greek Interpreter, Holmes's brother Mycroft Holmes appears. In such a case, the description for which the relevant name is short might have to be minimally revised so as to achieve unique reference in the fiction. In the Holmes stories, we can achieve this by slightly revising the relevant description to "the person named "Sherlock" to whom the fictional author of H refers with "Holmes"'. (Occurrences of 'Holmes' in which Mycroft is the pretended referent can then be replaced by another suitably revised description.)

A more serious problem arises when we try to further analyze a proposal like (26a) in terms of Currie's analysis (TF) of truth in fiction. The result is

(26b) It is reasonable (to degree $\mathrm{r}$ ) for the informed reader of $\mathrm{H}$ to infer that the fictional author of $\mathrm{H}$ believes that the referent $\mathrm{FAH}_{\mathrm{FH}}$ of 'Holmes' is a pipe smoker.

The problem here is that if we read the metalinguistic description 'the referent FAH $_{\text {of }}$ "Holmes" as having small scope relative to 'believes that', then we get a false result. For (26b) would then imply the falsehood that the fictional author believes that his story $\mathrm{H}$ has a fictional author! To avoid this problem, we need to add a clause to (TF) stipulating that, for any fictional name $\mathrm{N}$ that occurs in the relevant instance of ' $\mathrm{p}$ ' in the definiens of (TF), $\mathrm{N}$ must have large scope relative to the operator 'the fictional author of S believes that' and small scope relative to 'infers that'. The resulting revision of (26b) is then unproblematic:

(26c) It is reasonable (to degree $r$ ) for the informed reader of $\mathrm{H}$ to infer that the referent $\mathrm{FAH}_{\mathrm{FH}}$ of 'Holmes' is such that the fictional author of $\mathrm{H}$ believes that he is a pipe smoker. 
This revised proposal has the nice effect that metafictive uses of fictional names really only ascribe de re beliefs about various characters in the fiction to the fictional author, so that the truths of fiction expressed by our metafictive uses of names are all pretended to be singular propositions, even though in our uses, the names are short for descriptions. ${ }^{20}$

\section{Abstract mythical beings and fictional characters.}

Kripke (2013) provides a plethora of useful and persuasive examples in his attempt to show that we often use names from myth and fiction as genuine terms to refer to abstract mythical beings and fictional characters. ${ }^{21}$ Van Inwagen (1977) and Currie (1990) also provide useful examples to the same end in the case of names from fiction. I am not convinced by these examples, most of which I take to be disguised metamythic or metafictive uses of names, in which, as I argued above, the names are used as short for descriptions. For instance, Kripke (2013) gives the following examples:

(28) Hamlet is a fictional character. (p. 61.)

(29) There is such a fictional character as Hamlet. (p. 72.)

I take it that to use a name $\mathrm{N}$ in a sentence like (28) is to say something which logically implies ' $\mathrm{N}$ does not actually exist'. So it seems to me that (28) means

(28a) Hamlet does not exist; rather, there is a fiction F such that in F, Hamlet is a character.

I would also suggest that to be a character in a fiction is to be a subject of predication in that fiction, so that (28) and (28a) are both equivalent to

(28b) Hamlet does not exist; rather, there is a fiction F such that in F, Hamlet is a subject of predication.

\footnotetext{
${ }^{20}$ This de re effect also allows my view to avoid various nice problems regarding modal truths in fiction that were brought home to me by Ben Caplan (in correspondence). One such problem goes like this. It certainly should be true that

(i) In the fiction $\mathrm{H}$, it is possible that Holmes exists, even though 'Holmes' has no referent. But if in (i), as I propose, 'Holmes' is short for 'the referent ${ }_{\mathrm{FAH}}$ of "Holmes", then (i) would be false, if 'Holmes' has small scope relative to 'it is possible that'. But on the revised analysis of (i) that I just proposed, the problem disappears, for we just get the truth:

(ii) It is reasonable (to degree $\mathrm{r}$ ) for the informed reader of $\mathrm{H}$ to infer that the referent ${ }_{\mathrm{FAH}}$ of 'Holmes' is such that the fictional author of $\mathrm{H}$ believes that it is possible that he exists, even though 'Holmes' has no referent.

${ }^{21}$ Anthony Everett calls this view regarding names from fiction 'fictional realism', and in his 2005, he raises some serious problems for the view. Schneider and von Solodoff (2009) propose objections to Everett's arguments, and Caplan and Muller (2014) defend Everett's arguments against these objections. My objections to the Kripke/van Inwagen view are distinct from Everett's objections, and my view of the semantics of fictional names is distinct from Everett's view.
} 
As I argued above, any name in a (partly metafictive) context like this is being used as short for a description, and so is not being used as a name of an abstract entity.

While (28) is true on my analysis, Kripke's example (29) is false. (29) certainly seems to be true, since it appears to be logically equivalent to (28), which is true. But (28) and (29) are equivalent only if the context 'is a fictional character' is extensional. But on my analysis of (28), this context is not extensional, and so (28) does not imply (29). In fact, given the analysis (28a), (28) implies that (29) is false.

Another class of cases which Kripke (2013) discusses at length are cases where it appears that a person is said (truly) to bear a two-place relation to a mythical being or fictional character, cases such as

(30) The ancient Greeks worshipped Zeus.

(31) Jones [a literary critic] admires Desdemona.

One oddity of Kripke's appeal to such cases is that, rather than supporting his view, these cases actually seem to refute that view. For while (30) is true and (31) could be true, they would both be false if in them the names 'Zeus' and 'Desdemona' referred to abstract entities. For surely, the Greeks did not worship any abstract entity when they worshipped Zeus; nor would any literary critic be admiring an abstract entity when admiring Desdemona, or be pitying an abstract entity when pitying Anna Karenina.

It remains to explain how sentences like (30) and (31) could be true. I will have to skip discussion of cases like (31), since their explication would require a full theory of emotion in fiction. ${ }^{22}$ I will concentrate instead on Kripke's discussion of (30). Kripke argues that the verb 'worship' expresses a two-place relation. I agree that on one of its meanings, 'worship' expresses the mental two-place relation that a person $x$ bears to an entity $y$ just in case $x$ "reveres, adores, or venerates" y as a deity. (See Webster's New World Dictionary, 1982 edition.) But on this meaning, (30) will just be either false or without truth value, since 'Zeus' will either be an empty name or description, or perhaps will be a name that refers to an abstract object (which no one has ever worshipped).

However, 'worship' has a second meaning on which it is an intransitive verb meaning to engage in worship, that is, to perform various ritualistic activities such as prayer, sacrifice, etc. (Again, see Webster's New World Dictionary.) In this sense, 'worship' resembles the intensional verbs 'seek', 'look for', 'search for', and 'want', as they were discussed by

\footnotetext{
${ }^{22}$ See for instance the theory of emotion in fiction proposed by Currie in Chapter 5 of his (1990). Given this theory, it is not difficult to construct a plausible explication of sentences like (31) on which the relevant names from fiction do not refer to abstract characters.
} 
Alonzo Church (1958, p. 8, note 20) and W.V.O. Quine (1960, 155-156). Church gave the example

(32) Schliemann sought the site of Troy.

Church pointed out that there is a sense in which (32) would be true, even had the site of Troy never existed. So he suggests that 'sought', rather than expressing a two-place relation, is an operator that forms intensional contexts. Kripke (2013, 68-69) discusses Church's suggestion at length, arguing that the suggestion will not work for 'worship', on the grounds that 'worship' expresses only a two-place extensional relation. But again, Kripke is wrong about this.

Church's example (32) can usefully be understood as

(32a) Schliemann sought with the intention (purpose, goal) of finding the site of Troy.

Similarly, the oft-mentioned example 'Ponce de Leon searched for the fountain of youth' becomes

(33) Ponce de Leon searched with the intention (purpose, goal) of finding the fountain of youth.

The verbs 'seek' and 'search for' form intensional contexts because they express types of action that are necessarily goal directed. The intransitive sense of 'worship' also expresses a type of necessarily goal directed activity. Thus Kripke's sentence (30) ('The ancient Greeks worshipped Zeus') has a reading similar to (32a) and (33):

(30a) The ancient Greeks engaged in various ritualistic activities with the intention (purpose, goal) of expressing their devotion to, reverence for, or adoration of Zeus.

Here, the fact that 'Zeus' is an empty term does not affect the truth of (30a), since 'Zeus', which I take to be short for a description like 'the most powerful of the gods, whose name is "Zeus", occurs in the scope of a cognitive operator.

Before closing, I should discuss cases of the sort that Currie $(1990,171)$ calls transfictive. Here are three transfictive cases:

(34) Holmes's methods are quite different from those of Poirot. (Currie 1990, 171.)

(35) There are characters in some $19^{\text {th }}$ century novels who are presented with a greater wealth of detail than any character in any $18^{\text {th }}$ century novel. (van Inwagen, 1977, 302.) 
(36) Falstaff and Iago are two of the most charming characters in literature. (Kripke 2013, 62.)

Kripke, van Inwagen, and Currie are all convinced that in cases like (34) and (36), the names must be taken to refer directly to abstract characters. My own view is that such cases are all metafictive. When the relevant fiction operators are missing, I hold that they are implicit, which frequently happens, as in sentences about fiction like 'Holmes is a pipe smoker'.

First, consider Currie's example (34). Currie holds that here, the names 'Holmes' and 'Poirot' refer to abstract entities that he calls roles. According to Currie, (34) says that the methods of detection that partly define the Holmes role are quite different from the methods of detection that partly define the Poirot role $(1990,174)$. I agree that (34) does say something much like this, but we don't need to suppose that 'Holmes' and 'Poirot' refer to the relevant roles in (34). Rather, we can simply say

(34a) In the fiction $\mathrm{H}$, Holmes uses a set of methods $\mathrm{M}$, while in the fiction P, Poirot uses a set of methods $\mathrm{M}^{*}$, and the methods in $\mathrm{M}$ are quite different from the methods in $\mathrm{M}^{*}$.

Here, we may assume that the names 'Holmes' and 'Poirot' are short for the relevant descriptions as before.

Both van Inwagen and Currie claim that van Inwagen's example (35) involves quantification over fictional characters. But this claim becomes doubtful when we give the phrase 'in some $19^{\text {th }}$ century novels' largest scope in (35). If we simplify somewhat by replacing the plural quantifiers in (35) with singular ones, (35) can be plausibly understood to mean

(35a) There is at least one $19^{\text {th }}$ century novel $F$ such that in F, $d_{1}$ is the degree of detail provided by the properties ascribed to a given character, and for every $18^{\text {th }}$ century novel $G$ and any set of properties $S$, if in $G, S$ is ascribed to some character, then the degree $d_{2}$ of detail provided by $S$ is less than $d_{1}$.

My overall suggestion is that comparisons of characters across fictions amount to comparisons of aspects of the sets of properties ascribed to characters in the relevant fictions.

In (35a), I used a suggestion by Edward Zalta that comparisons of fictional characters can often be analyzed in terms of the degrees to which the characters have given properties. (See Zalta (2000), 130-134.) The same device also provides an adequate analysis of Kripke's challenging case (36). Let ' $H$ ' name the combination of the two Henry IV plays in which Falstaff appears, and let ' $\mathrm{O}$ ' abbreviate Othello. Then we can analyze (36) as 
(36a) In $\mathrm{H}$, Falstaff has charm to degree $\mathrm{d}_{1}$ and in $\mathrm{O}$, Iago has charm to degree $\mathrm{d}_{2}$, and $\mathrm{d}_{1}$ and $d_{2}$ are among the highest degrees of charm in the set $D$, where a degree $d$ is a member of $\mathrm{D}$ iff in some fiction $\mathrm{F}$, some character has charm to degree $\mathrm{d}$.

As in (34a), the names in (36a) occur in metafictive contexts, and so are short for the relevant descriptions as before.

My metafictive analyses of examples (34), (35) and (36) provide good prima facie evidence that the names in such cases do not refer directly to abstract characters. So given our previous discussion of other examples in sections 7,8 and 9, the best general hypothesis would seem to be that in our talk about both myth and fiction, names from myth and fiction are used as abbreviated definite descriptions.

\section{Conclusion.}

The DR-thesis is often assumed to imply that names are never used as abbreviated definite descriptions. But this assumption results in an unfortunately narrow and inaccurate account of the way names work in natural language. What is true is that the fundamental, dominant way in which names are used is their use as directly referring genuine terms, and not as short for descriptions. But this allows for the possibility that natural languages contain idioms on which in a few types of contexts, names can be used as short for descriptions. Here, I've proposed a way in which such an idiom might be based on the semantic properties of one relatively rare class of names, the descriptive names. The great advantage of this hypothesis is that it provides a general account of most of the examples of sentences containing empty names that are nevertheless regarded as obviously true by most speakers. In particular, I contended that the idiom hypothesis provides the only plausible account of the way names are used in substantive (as opposed to pointless) positive and negative existentials, and I argued against alternative views proposed by Braun and by Adams and Stecker.

Extending the idiom hypothesis to uses of names from myth, I argued that such names are short for descriptions in both metamythic and cognitive contexts, as well as in positive and negative existentials. I gave similar arguments for similar consequences regarding names from fiction as used in both metafictive contexts and in existentials. With the help of Currie's theory of truth in fiction, I proposed an idiom on which, in our talk about fiction, we use names from fiction as abbreviations of a certain form of definite description. Finally, I surveyed some of the main types of example that have been used to support the view that the 
names from myth and fiction in these examples must be used as directly referring genuine terms whose referents are abstract objects. I proposed analyses of these cases on which the names are not used to refer to abstract entities, but are rather used as short for descriptions. One advantage of my view is that it provides a unified account of the semantics of names, as we use them to talk about myth and fiction.

Acknowledgements. I am grateful to Ben Caplan for useful correspondence on these matters. Also, I would like to thank the students in my seminar in philosophy of language for their useful points and questions concerning this material, especially: David Baxter, Travis Figg, Joe Hinkins, Mark Reynolds, Jim Schwartz, Khristy Wilkinson, and Tom Wood.

\section{References}

Adams, F. and Stecker, R. (1994). "Vacuous singular terms". Mind and Language 9(4): 387-401.

Adams, F. and Dietrich, L. (2004). “What's in a(n empty) name”. Pacific Philosophical Quarterly 85: 125-148.

Braun, D. (1993). “Empty names”. Noûs 27(4): 449-469.

Caplan, B. and Muller, C. (2014). “Against a defense of fictional realism”. Philosophical Quarterly 64: 211224.

Braun, D. (2005). "Empty names, fictional names, mythical names”. Noûs 39(4): 596-631.

Church, A. (1956). Introduction to Mathematical Logic. Princeton: Princeton University Press.

Currie, G. (1990). The Nature of Fiction. Cambridge: Cambridge University Press.

Evans, G. (1982). The Varieties of Reference. Oxford: Oxford University Press.

Everett, A. (2005). “Against fictional realism”. Journal of Philosophy 102: 624-649.

Frege, G. (1891). "Function and concept". In P. Geach and M. Black (eds.), Translations from the Philosophical Writings of Gottlob Frege. Oxford: Basil Blackwell (1966): 21-41.

Frege, G. (1892). “On sense and reference”. In P. Geach and M. Black (eds.), Translations from the Philosophical Writings of Gottlob Frege. Oxford: Basil Blackwell (1966): 56-78.

Green, M. (2007). "Direct reference, empty names, and implicature”. Canadian Journal of Philosophy 37(3): 419-448.

Grice, P. (1989). Studies in the Way of Words. Cambridge, Mass.: Harvard University Press.

Hamilton, E. (1953). Mythology. New York: The New American Library.

Kaplan, D. (1989). “Demonstratives”. In J. Almog, J. Perry, H. Wettstein (eds.), Themes from Kaplan. Oxford: Oxford University Press.

Kripke, S. (1972a). "Naming and necessity". In D. Davidson and H. Harman (eds.), Semantics of Natural Language. Dordrecht: D. Reidel. 253-355.

Kripke, S. (1972b). “Addenda”. In D. Davidson and H. Harman (eds.), Semantics of Natural Language. Dordrecht: D. Reidel. 763-769.

Kripke, S. (2013). Reference and Existence: the John Locke Lectures. Oxford: Oxford University Press.

Lewis, D. (1970). "How to define theoretical terms". Journal of Philosophy 67: 427-446.

McKinsey, M. (1978). "Names and intentionality”. Philosophical Review 87(2): 171-200.

McKinsey, M. (1984). “Causality and the paradox of names”. Midwest Studies in Philosophy 9: 491-515. 
McKinsey, M. (1986). “Mental anaphora”. Synthese 66(1): 159-175.

McKinsey, M. (1994). “Individuating beliefs". Perspectives in Philosophy 8, Logic and Language: 303-330.

McKinsey, M. (1999). “The semantics of belief ascriptions”. No ûs 33(4): 519-557.

McKinsey, M. (2006). "Direct reference and logical truth: a reply to Lasonen-Aarnio". Dialectica 60(4): 447451.

McKinsey, M. (2010). “Understanding proper names”. Linguistics and Philosophy 33(4): 325-354.

McKinsey, M. (manuscript). "Reference failure, logical truth, and a posteriori necessity".

Moore, G. (1936). “Is existence a predicate?”. In G.E. Moore, Philosophical Papers. New York: Collier Books (1956): 114-125.

Plantinga, A. (1974). The Nature of Necessity. Oxford: Oxford University Press.

Quine, W. (1960). Word and Object. Cambridge, Mass.: MIT Press.

Russell, B. (1905). “On denoting”. In Bertrand Russell, Logic and Knowledge:Essays 1901-1950. MacMillan (1956): 41-56.

Russell, B. (1918). “The philosophy of logical atomism”. In Bertrand Russell, Logic and Knowledge:Essays 1901-1950. MacMillan (1956): 177-281.

Russell, B. and Whitehead, A.N (1910). Principia Mathematica to *56. London: Cambridge University Press, 1962.

Salmon, N. (1998). "Nonexistence”. Noûs 32(3): 277-319.

Schneider, B. and von Solodkoff, T. (2009). "In defense of fictional realism”. Philosophical Quarterly 59: 138149.

Searle, J. (1958). “Proper names”. Mind 67: 111-173.

Strawson, P. (1950). “On referring”. Mind 59: 320-344.

van Inwagen, P. (1977). “Creatures of fiction”. American Philosophical Quarterly. 14(4): 299-308.

Zalta, E. (2000). "The road between pretense theory and abstract object theory". In A. Everett and T. Hofweber (eds.), Empty Names, Fiction, and the Puzzles of Non-Existence. Stanford: CSLI Press. 117-147. 